\title{
Reduced fertilizer rates enhanced nitrogen use efficiency and decreased nitrogen loading in paddy rice - wheat long-term rotational cropping in Chao Lake watershed, East China
}

\author{
NEBIYOU Hadush ${ }^{1}$, Manqin Gan ${ }^{1}$, Peishi Liu ${ }^{1}$, Yu Huang ${ }^{1}$, Hongjun $\mathrm{Xu}^{2}$, and Ma \\ Youhua $^{1}$ \\ ${ }^{1}$ Anhui Agricultural University \\ ${ }^{2}$ Anhui Province People's Government
}

October 16, 2020

\begin{abstract}
Fertilizer application in excess of plant nitrogen requirements, leading to nitrogen use inefficiency has become main culprit of nitrogen surplus, posing nonpoint pollution threats. Chao Lake has been recipient of nitrogen loadings, mainly coming from the agroecosystem surrounding it. This study was conducted in Chao Lake watershed to assess nitrogen use efficiency, crop yield and nitrogen loading, using reduced and conventional fertilizer rates, based on ten years field monitoring and experiment. Paddy rice - wheat rotational tillage arranged in a completely randomized design using 30m2 treatment plots was employed to study hypothesis. Three indicators namely agronomic efficiency (kgkg-1), recovery efficiency (\%) and partial factor productivity (kgkg-1) were considered for nitrogen use efficiency. For nitrogen loading, nitrogen loading (kg ha-1yr-1), nitrogen runoff loss ratio (\%) and net nitrogen runoff loss ratio (\%) were taken. Results revealed, empirical formula of an exponential model explains the relationship. Reduced fertilizer levels produced high nitrogen use efficiency, high economic yield and less nitrogen loading. Nitrogen use efficiency was in order of: reduced $>$ high $>$ conventional fertilization treatments, while it decreased in ten years (2008 -2018) across all treatments. Nitrogen loading increased in ten years, both for rice and wheat growing seasons. Runoff volume influenced nitrogen loading more than other environmental factors considered. Such strategies that further reduce fertilizer levels by accounting for excessive supplies are critically important to consolidate effective nitrogen management measures.
\end{abstract}

\section{Introduction}

Owing to its detrimental role, together with potassium $(\mathrm{K})$ and phosphorus $(\mathrm{P})$, nitrogen $(\mathrm{N})$ is regarded as most essential nutrient in crop production (Luce 2013). Global crop yield growth by nine-fold in the last six decades was mainly attributed to $\mathrm{N}$ fertilizer (Ju et al. 2009, Lassaletta et al. 2014, Meng et al. 2016), while this same increase also led to sharp drop of nitrogen use efficiency (NUE) from $68 \%$ to $47 \%$. In China, fertilizer input in agriculture grew by $271 \%$ between 1997 and 2005 (Meng et al. 2016), that accounts about $30 \%$ of the global fertilizer use today. However, NUE decreased to a level below the world average $(28 \%$ compared to 47\%) in the process (Lassaletta et al. 2014). As a result, inorganic N storage has increased significantly (Nie et al. 2017). Consumption involving beyond recommended limit applications is considered to be the main culprit (Hansen et al. 2018, Meng et al. 2016, Fan et al. 2011, Yang et al. 2017). Applications of 30 to $60 \%$ in excess of recommended rates is observed in China (Ju et al. 2009). Hence, the excessive application in turn reducing NUE leads to increased loss of reactive N (Carpenter et al. 1998, Chen et al. 2013, Mellander et al. 2012), solubility and mobility of which (Swaney and Howarth 2019) pose significant environmental effects. The surplus use of $\mathrm{N}$ fertilizer elucidates the poor understanding of its transformation mechanisms and its mobility and in turn cascading effects, across the farming communities. Furthermore, 
with continuous input, yield return can start to decrease starting some fixed amount (Lassaletta et al. 2014, Jin et al. 2012, Meisinger et al. 2008) called as the diminishing return; which could be attributed to toxicities of ions such as aluminum (Al) (Schroder et al. 2011). Hence it is imperative to understand how fertilizer modifies biogeochemical cycles using the two large $\mathrm{N}$ pools, the atmosphere $\left(\mathrm{N}_{2}, \mathrm{~N}_{2} 0, \mathrm{NH}_{3}\right)$ or soil (reactive $\mathrm{N}$ from stored $\mathrm{N}$, organic matter etc.). In China, the interaction of excess $\mathrm{N}$ with the underlining $\mathrm{N}$ cycle processes leading to acidification and toxification (Barak et al. 1997), diffuse pollution, GHG emission etc. (Hauck 1981), have become major environmental concerns (Fan et al. 2011).

Optimizing crop $\mathrm{N}$ input, through reducing the input levels but increasing or at least maintaining the yields (Luce 2013), it avails comprehensive solution in agroecosystems. According to Ju et al. (2009) N loss from farmlands can be halved without losing yield through optimal adjustment, by applying only $50 \%$ of what is normally applied for the conventional case. N optimization has also increased crop yield through integrated soil-plant system management (Fan et al. 2011, Meng et al. 2016). However, two issues arise 1) optimum rates vary substantially within and between spatial and temporal gradients 2) except for controlled environments, yield uncertainties dominate in conventional agroecosystems. Hence, long term, continuous and reliable estimates of soil $\mathrm{N}$ supplies, budget trends and soil/plant/microorganism systems can address some of the issues. Whereas, unfortunately most studies depend on less comprehensive and short-term field monitoring results.

Chao Lake, as one of the five largest fresh water lakes in China (Chen et al. 2013, Ni et al. 2018), is material to the surrounding, by supplying water, availing facility for transport etc. It also contributes towards maintaining biodiversity and regulating climate; however, the lake is frequently reported to be highly eutrophic (Peng et al. 2019). The lake sits with in subtropical monsoon region, where, the major cropping system is rice - winter crop rotational cropping (Wang et al. 2015), regarded as main contributor of $\mathrm{N}$ and $\mathrm{P}$ exports (Zhou and Gao 2011, Wang et al. 2015).

Hence, due to the aforementioned realities, in this study we sought to understand how different levels of optimized $\mathrm{N}$ fertilizations with reduced rates might contribute to increasing NUE and reducing $\mathrm{N}$ loss, by maintaining the crop grain and biomass yields, on a long-term basis. We employed experimental method for different fertilization treatments on the traditional wheat - rice rotational cropping method. We evaluated relationships among; yield, NUE and runoff loading on one hand and different fertilization rates of: conventional, high, and reduced fertilizer levels, on the other hand.

\section{Area description}

The experiment was conducted in Chao watershed, near Chao lake (2 kms away), situated at $117^{\circ} 47 / 35^{\prime \prime} \mathrm{N}$ and $31^{\circ} 38 / 45^{\prime \prime}$ E, $17 \mathrm{~m}$ above sea level. Its sits with mild characteristic climate and abundant light. The site's annual average precipitation is $996 \mathrm{~mm}$ and its annual average temperature is $16{ }^{\circ} \mathrm{C}$. Rainy season extends from May to October. Chao Lake is found in between Yangtze and Huaihe rivers in the southeast China, at the periphery of Hefei city, the capital of Anhui province. Thirty-three rivers and tributaries discharge in to the lake body.

\section{Experimental design}

Five treatments were tested in paddy rice - wheat rotational tillage system. The treatments were arranged in a completely randomized design with three replications. The treatments are, CK (blank treatment), CFT (Conventional Fertilization Treatment), HFT (High fertilization Treatment), RFT (Reduced Fertilization Treatment) and RFTS (Reduced Fertilization Treatment plus Straw addition). Detail information of treatments along with their application rates are summarized in Annex 1. Urea ( $46 \% \mathrm{~N})$, calcium superphosphate $(12 \% \mathrm{P})$ and potassium chloride $(60 \% \mathrm{~K})$ were used. Wheat Ningmai 13 variety and Wandao 153 hybrid rice were used as a test crop. Straw nitrogen contents were $0.54 \%$ and $0.81 \%$ in wheat and rice straw, respectively. Area of the experimental plot was $30 \mathrm{~m}^{2}(4 \mathrm{~m} * 7.5 \mathrm{~m})$; it was surrounded by concrete ridges. Concrete runoff harvester having $2.4 \mathrm{~m}^{3}(2 \mathrm{~m} \mathrm{~L} * 1 \mathrm{~m} \mathrm{~W} * 1.2 \mathrm{~m} \mathrm{H})$ storage volume was constructed to measure runoff volume following rainfall events. 
The treatment plots were irrigated twice. Water level was allowed to fluctuate between 5 and $10 \mathrm{~cm}(300-$ $600 \mathrm{~m}^{3} \mathrm{ha}^{-1}$ ) throughout the rice-growing season.

\section{Sample collection}

(1) Runoff volume was estimated for all rainfall events that generated runoff by recording surface height of storage. In addition, for rice season runoff volume generated from plots during irrigation was measured. Plots were only irrigated during the rice season (June to August). Runoff volume was taken when the pool reaches $80 \%$ of its capacity. Pools were being continuously stirred with clean bamboo rods before taking samples from different sides and depth. After runoff was carefully stirred samples were taken with $500 \mathrm{ml}$ bottles and the samples were transported for immediate lab analysis. The samples were subjected for total nitrogen, $\mathrm{NO}_{3}$ and $\mathrm{NH}_{4}$ determination. When we were unable to analyze the samples on same sampling day, we store and preserve them in refrigerator at $-4^{0} \mathrm{c}$. The runoff water was discharged and cleaned after sampling was done to harvest runoff from the subsequent rainfall event.

(2) Grain and biomass yield data were recorded in the field. Samples of biomass (before threshing) and grain yields were also been collected from five points of an "X" shaped scheme for Lab analysis. Grain and biomass samples were taken to laboratory, oven dried at $105^{\circ} \mathrm{c}$, weighted, and subjected for total nitrogen $(\mathrm{TN})$, total phosphorus and total potassium determinations.

(3) Five composite soil samples were taken after rice harvest from the upper 0-20 cm layer, using the same approach as used in the plant sampling. Collected samples were taken to laboratory, air dried, grinded and sieved using 0.25 and 2 mesh sizes. Soil samples were subjected for $\mathrm{pH}$, moisture content, organic matter, total nitrogen, $\mathrm{NO}_{3}$ and $\mathrm{NH}_{4}$ determinations.

\section{Laboratory analysis}

$\mathrm{pH}$ was determined on 1:2 (soil to water solution) ratio by using a glass electrode. Total nitrogen was determined by alkaline persulfate oxidation digestion technique without filtration. $\mathrm{NH}^{+}$and $\mathrm{NO}^{-}$were determined by continuous flow injection method using Analytical AA3 HR Nutrient Autoanalyzer instrument. Plant samples were first digested by $\mathrm{H}_{2} \mathrm{O}_{2}-\mathrm{H}_{2} \mathrm{SO}_{4}$; then the filtrate was subjected to total nitrogen by AA3 continuous flow injection. Soil organic matter was determined by potassium dichromate oxidation-external heating method.

\section{Data analysis}

To analyze nitrogen input on the field, information on fertilizer application, mineralization, irrigation nitrogen, seed and straw addition were considered, while for nitrogen output, from field information on crop nutrient uptake, runoff, volatilization, denitrification were used. Soil residual nitrogen was continuously determined using formula (1) to know nitrogen balance.

soil nutrient content of current year - soil nutrient content of the preceding year

Soil weight was estimated based on equation (2).

Mass in $\mathrm{kg} *$ bulk density $* 0.2 \mathrm{~m} * 30 \mathrm{~m}^{2}$

To estimate mineralization, we used equation (3).

$(\mathrm{SOM} \mathrm{kg} / 100 \mathrm{~kg}$ soil $) *($ weight $\mathrm{kg} / \mathrm{ha}$ in $20 \mathrm{~cm}$ depth $) *(5 \mathrm{~kg} \mathrm{~N} / 100 \mathrm{~kg} \mathrm{SOM}) *(1 \mathrm{~kg} \mathrm{SOM}$ mineralized $/ 100 \mathrm{~kg}$ $\mathrm{SOM})$

We assumed $5 \% \mathrm{~N}$ content in organic matter. Volatilization was taken from published paper conducted on the same site, also funded by same project (national monitoring project) (Xiaohong et al. 2012). For nitrogen usage efficiency we took three indicators namely: Agronomic Efficiency (Veneklaas et al.), Recovery Efficiency (RE) and Partial Factor Productivity (PFP).

(4) $\mathrm{AE}(\mathrm{kg} / \mathrm{kg})=\mathrm{Yn}-\mathrm{Yck} / \mathrm{FN}$ 
(5) RE $(\%)=$ Yun - Yuck/ FN

(6) $\operatorname{PFP}(\mathrm{kg} / \mathrm{kg})=\mathrm{Yn} / \mathrm{FN}$

Where: Yn is yield of a given fertilized treatment; Yck is yield of the blank treatment; Yun is plant nitrogen uptake of a given fertilized treatment; Yuck is plant nitrogen uptake of the blank treatment; FN is the nitrogen input fertilizer amount.

Nitrogen loss was calculated using three different indicators:

(7) Loading $\left(\mathrm{kg} \mathrm{ha}^{-1} \mathrm{yr}^{-1}\right)=\Sigma([\mathrm{NLi}+\mathrm{NLi}+1] / 2 *$ Runoff volume $)$

(8) Runoff loss ratio $(\%)=\mathrm{NLn} / \mathrm{FN}^{*} 100$

(9) Net runoff loss ratio $(\%)=$ NLn - NLck/ FN* 100

Where: NLi stands for nitrogen loading at a given time, while NLi stands for the sample taken after NLi. NLn stands for nitrogen loading of a given fertilized treatment, NLck stands for nitrogen loading of the blank treatment. In addition, RDA was used to assess the relationship between the environmental factors and the loading of nitrogen forms.

Frame work developed by European union experts' panel was used to evaluate nitrogen use efficiency (Heuer et al. 2017). Statistical analyses were performed using R and SPSS software, with critical $\alpha$ values of 0.05

and below. Shapiro-Wilk and Kruskal-Wallis rank sum were used for significant tests and Tukey HSD and Dunn were used for post hoc test. Sphericity of RDA was tested using KMO and Bartlett's test.

\section{Results and discussion}

The temporal arrangement was such that, extending for a period of six months, January to June, represents a wheat growing season, while the remaining period of the year (June to December) represents a rice growing season.

The experiment was set up in 2007. Physicochemical properties of top $20 \mathrm{~cm}$ layer in 2007 were: $\mathrm{pH}$ of 6.99 ; $34.07 \mathrm{gkg}^{-1}$ organic matter; $1.58 \mathrm{gkg}^{-1}$ total nitrogen; $0.78 \mathrm{gkg}^{-1}$ total phosphorus; $136.31 \mathrm{mgkg}^{-1}$ available $^{-1}$ potassium; $25.97 \mathrm{mgkg}^{-1}$ available phosphorus; and $168.54 \mathrm{mgkg}^{-1}$ alkali hydrolyzed nitrogen. Ten years (2008- 2018) later, soil moisture content (MC) became 16 to $50 \%$ (averaged at $31 \%$ ). Compared to wheat growing season (20 to $46 \%$, average of $29 \%$ ), rice growing season MC was higher. $\mathrm{pH}$ varied (median of 7.3) between 4.87 and 10.32 and, 6.55 and 8.23 for rice and wheat growing seasons, respectively. Similarly, soil organic matter $(\mathrm{SOM})$ was $25.3 \pm 6 \mathrm{~g} \cdot \mathrm{kg}^{-1}$ and $26.4 \pm 5.5 \mathrm{~g} \cdot \mathrm{kg}^{-1}$ for rice and wheat growing seasons, respectively.

Mean monthly rainfall peaks between June and August (Fig 1), during when plots were also submerged (irrigated). Measurements showed that, the rainfall regime significantly $(\mathrm{r}=0.72)$ influenced runoff volume, which in turn affects $\mathrm{N}$ loss (also discussed in the $\mathrm{N}$ loading section below). The rainfall depth and its subsequent runoff volume affect nutrient loss in agroecosystems (Hahn et al. 2012, Wang et al. 2013) due to fertilizer applications. A total of 97 runoff events were counted in ten years. Total runoff yield from the six treatments was $562.47 \pm 5.71 \mathrm{~mm} \mathrm{plot}^{-1} \mathrm{yr}^{-1}$. With a $45.5 \pm 0.5 \mathrm{~mm} \mathrm{plot}^{-1} \mathrm{yr}^{-1}$ yield, RFTS treatment produced slightly lower runoff yield compared to the remaining average $\left(46.8 \pm 0.5 \mathrm{~mm} \mathrm{plot}^{-1} \mathrm{yr}^{-1}\right)$. Comparing the two subject seasons of the study, significantly higher runoff yield was observed during rice growing season.

\section{Fig 1 near here}

Runoff yield increases as a result of one or more of the following soil attributes, a) low permeability and early saturation (Wang et al. 2015) b) high clay content (Follett 2008), c) high water tables due to shallow aquifer (Follett 2008). In our case, although no statistical difference was observed among treatments for yield, the straw addition was able to reduce up to $3 \%$, whereas, straw has reduced $21 \%$ runoff yield in another study in China (Wang et al. 2015). Among the attributes mentioned above (a-c), decreased permeability leading 
to early saturation and in turn flooding, triggered the runoff yield in this study, the reasons being 1) less permeable plow pan (Ji et al. 2011, Wang et al. 2015) and; 2) saturation of the water table (Wang et al. 2015). In addition to the first reason mentioned, due to higher rainfall, irrigation and water logging in rice growing season, runoff yield in rice growing season also outweighs yield from wheat growing season.

\section{Nitrogen loading}

The nitrogen export indicators namely, nitrogen loading, nitrogen runoff loss ratio and net nitrogen runoff loss ratio were calculated based on the arithmetic functions provided above (formulas 7 to 9). Results indicated no significant difference for combinations of any of those indictors and the fertilization treatments. Whereas, although not significant, CFT and HFT produced relatively higher N loading. RFT treatment produced the lowest $\mathrm{N}$ loading. The summary of loading results is presented in Table 1.

\section{Table 1 near here}

Average runoff loadings were $31.35 \pm 7.8 \mathrm{Kg} \mathrm{ha}^{-1} \mathrm{yr}^{-1}, 12.13 \pm 3.2 \mathrm{Kg} \mathrm{ha}^{-1} \mathrm{yr}^{-1}$ and $3.42 \pm 0.43 \mathrm{Kg} \mathrm{ha}^{-1} \mathrm{yr}^{-1}$ for TN, $\mathrm{NO}_{3}{ }^{-}-\mathrm{N}$ and $\mathrm{NH}_{4}{ }^{+}-\mathrm{N}$, respectively. The TN load estimated in this study was at least $18.9 \mathrm{~N} \mathrm{ha}^{-1} \mathrm{yr}^{-1}$ higher than previously reported amount by Anhui province environmental protection department (2011) (unpublished).

Relationships among the fertilization treatments and $\mathrm{N}$ loadings were further evaluated using the ordination plots in Fig 2. The plots, through their distance and proximity patterns illustrated that, $\mathrm{N}$ loading decreased in RFT and RFTS treatments, while it increased in HFT and CFT. As shown in the plots, runoff volume had the largest influence among the environmental factors. Likewise, $\mathrm{pH}$, soil moisture content and soil organic matter had great deal of influences to a differing degree. Soil residual nitrogen and input fertilizers, showed correlation to the reduced fertilization treatments, that indicates high nitrogen retention and less nitrogen loading in those two fertilization treatments (RFT and RFTS). In conclusion, both the above load indicators and the evaluation of RDA plots here clearly indicated that, $30 \%$ reduction of $\mathrm{N}$ fertilizer reduced $\mathrm{N}$ export effectively.

\section{Fig 2-Rice and Fig 2-Wheat near here}

$\mathrm{NO}_{3}{ }^{-}-\mathrm{N}$ loading was significantly higher compared with $\mathrm{NH}_{4}{ }^{+}-\mathrm{N}$, which could be attributed to microbial buildup of nitrate from ammonia (nitrification) (Zhang and Wang 2005), and to ammonium ion own structure to be sorbed to negatively charged colloidal particles (Zhou et al. 2016). Jia et al. (2018) explained such mobility as a tendency for $\mathrm{NH}_{4}{ }^{+}$to remain in the top layer and $\mathrm{NO}_{3}{ }^{-}$to be transported further distances. Temporally, loadings of all $\mathrm{N}$ forms $\left(\mathrm{TN}, \mathrm{NO}_{3}{ }^{-} \mathrm{N}\right.$ and $\left.\mathrm{NH}_{4}{ }^{+}-\mathrm{N}\right)$ increased significantly in ten years $(2008$ to 2018), which indicates increased $\mathrm{N}$ storage from excessive fertilizer applications. In agreement to this, the bi-variate Pearson correlation in Table 2 also shows, input fertilizer to have high correlation (r) with residual soil nitrogen and with runoff $\mathrm{TN}$ and runoff $\mathrm{NO}_{3}{ }^{-} \mathrm{N}$ concentrations. These are also in congruent to the results revealed in the argument discussed below (NUE decline in ten years, Fig 6).

\section{Table 2 near here}

Season wise, although rice growing season received more rainfall depth than wheat growing season, higher nitrogen loading was occurred in wheat season, except for $\mathrm{NH}_{4}{ }^{+}$-N. Similar results were reported in other studies (Ju et al. 2009, Wang et al. 2019). Buffering effect of the concrete ridges contributed to the decrease of $\mathrm{N}$ loss. The water logging and its tendency to have high hydraulic retention enhance reductions of nitrogen export (Ju et al. 2009). In addition, in a submerged and in turn anerobic environment, denitrification (Patrick and Mahapatra 1968) and leaching (Gao et al. 2002) dominate nitrogen loss mechanisms. Moreover, according to Ji et al. (2011), plow pan break in alternating rice-wheat crop rotations coupled with high moisture leads to nitrate leaching than lateral transport in rice growing season.

\section{Input nitrogen and NUE}

Trajectories of input nitrogen versus their corresponding yield returns are shown in Fig 3 . The plots indicated high yield returns for $30 \%$ nitrogen reduction treatments. In general, exponential relationship was observed 
for input nitrogen versus yield trajectories, which was also suggested by similar agronomic papers. Hence, the function $\mathrm{y}=\mathrm{y}_{0}+\mathrm{a}^{*} \exp \left(-0.5^{*}\left(\mathrm{x}-\mathrm{x}_{0}\right) / \mathrm{b}^{2}\right)$ was found as best fit. As shown in the plots, all (except wheat grain yield) the yield trajectories namely, wheat biomass, rice grain and rice biomass showed a fixed optimum amount of " $\mathrm{X}$ " input nitrogen, that has a corresponding fixed maximum yield designated as $\mathrm{Y}_{\max }$, beyond which, further input nitrogen yields less crop/biomass yield. For wheat grain yield, $\mathrm{Y}_{\max }$ remained stable with variable "X".

In paddy rice growing season, the highest yield was achieved at an input fertilizer amount that is near to RFT treatment level. As shown in the plot (Fig 3 a and b), $Y_{\max }$ was reached at input levels of $152.5 \mathrm{~kg}$ $\mathrm{ha}^{-1} \mathrm{yr}^{-1}$ and $155.5 \mathrm{~kg} \mathrm{ha}^{-1} \mathrm{yr}^{-1}$, for grain and biomass yields, respectively, which are approximate amounts to the RFT treatment level $\left(157 \mathrm{~kg} \mathrm{ha}^{-1} \mathrm{yr}^{-1}\right)$. For wheat grain yield, $\mathrm{Y}_{\max }$ was reached at fertilizer input level of $94.71 \mathrm{~kg} \mathrm{ha}^{-1} \mathrm{yr}^{-1}$, which was lower compared to RFT treatment $\left(147 \mathrm{~kg} \mathrm{ha}^{-1} \mathrm{yr}^{-1}\right)$. RFTS treatment brought similar outcome. For wheat biomass, the highest yield was achieved at $195.9 \mathrm{~kg} \mathrm{ha}^{-1} \mathrm{yr}^{-1}$ input nitrogen, which was quite high compared to the reduced fertilization input amount, but lower compared to another study conducted in Huang-huai plain (Duan et al. 2019), where biomass yield began to decline at $240 \mathrm{kgha}^{-1}$. In an input nitrogen versus RE linear model (Ju et al. 2009), RE started to decrease $50 \mathrm{~kg} \mathrm{ha}^{-1}$ upwards for wheat grain in Taihu region (input amount was $153 \mathrm{~kg} \mathrm{Nha}^{-1}$ ); in the same study however, optimum rice yield agree with our finding (input amount of $200 \mathrm{~kg} \mathrm{Nha}^{-1}$ application) using a polynomial model (their $\mathrm{Y}_{\max }$ was $\sim 150 \mathrm{~kg} \mathrm{ha}^{-1}$ ). The remaining two fertilization treatments (CFT, HFT) are situated towards the diminishing return side of the trajectories and opposite to one another, as can be seen from Fig 3. Blank treatment fell within the mining range (similar result was also observed in Fig 5).

The present study clearly demonstrated minimized yield response to constant input nitrogen led to surplus of the not assimilated/immobilized nitrogen in the soil.

\section{Fig 3-a, Fig 3-b, Fig 3-c, Fig 3-d near here}

Both AE and PFP decreased significantly across and within the ten study years (2008 - 2018) (Fig $4 \mathrm{c}$ and d). For rice growing season, AE and PFP were $16 \mathrm{kgkg}^{-1}$ and $42.9 \mathrm{kgkg}^{-1}$, respectively, while for wheat growing season AE and PFP were $19.5 \mathrm{kgkg}^{-1}$ and $35 \mathrm{kgkg}^{-1}$, respectively. Obviously RFTS and RFT demonstrated higher efficiency compared to CFT and HFT (Fig $4 \mathrm{a}$ and b). This agrees with the National Bureau of Statistics of China (2010) report (Unpublished), that emphasized the significant reduction of AE and PFP over 30 years period. In contrast, although HFT showed significantly lower PFP than both RFT and RFTS, it showed no significance difference in AE, despite lower result. Likewise, the trends observed in wheat growing season were quite similar, where, HFT and CFT showed lower AE and PFP than RFT and RFTS, however there was no statistical difference except for CFT being significantly lower than both RFT and RFTS in PFP.

RE remained stable in ten years, with only rare cases displaying significant fluctuations. For rice growing season, RE reached the lowest (14.37\%) and highest (48\%) edges in 2013 and 2015, respectively. Based on the overall efficiency, CFT (30.2\%) was significantly lower than both RFT and RFTS. For wheat growing season on the other hand, lowest RE was measured at $14.7 \%$ in 2015 , while its overall average became $36.8 \%$.

In summary, all the three NUE indicators namely, AE, RE and PFP, demonstrated similar pattern of the order RFT $>$ RFTS $>$ HFT $>$ CFT usage efficiency. The result of this study agrees with previous studies (Meisinger et al. 2008, Srivastava et al. 2018), in that above an optimum level, the NUE decreases with increased rate. RE has been reported to continuously decrease throughout years in China except in controlled experiments, for example, Veneklaas et al. (2012) reported $28.3 \%$ and $28.2 \%$ RE reductions for rice and wheat, respectively. In a controlled field experiment on the other hand, Cassman et al. (2002) found 50 to $80 \%$ RE.

\section{Fig 4-Rice and Fig 4-Wheat near here}

In the NUE framework that is based on the TN input output balance shown in Fig 5, three type of groups were identified namely 1) the control treatment dominantly felling above the $90 \%$ NUE margin. This area is 
also called "the mining range"; 2) RFTS and RFT treatments both completely felling in the area between the 50 to $90 \%$ NUE lines called as "the desirable range". Some points of CFT and HFT treatments were observed in this range; 3) CFT and HFT dominantly felling below the 50\% margin. The area is known as "risk of inefficient $\mathrm{N}$ use range". In addition, based on the optimum rates identified in this study, we drew a constant horizontal line of $113 \mathrm{~kg} \mathrm{~N} \mathrm{ha}{ }^{-1} \mathrm{yr}^{-1}$ to serve as reference point. Accordingly, as can be seen from the plot, most CK points fell below the line. Whereas, interestingly there were CK cases above this horizontal line too, which indicates the availability of quite significant residual nitrogen storage in the soil. In line with this result Li et al. (2016) found significant TN storage in long term fertilized agroecosystems.

\section{Fig 5 near here}

Regarding grain and biomass yield, studies recommend careful timing of fertilizer applications by splitting it into plant growth stages to match the physiological requirements and in turn facilitate gradual assimilation of nutrients (Fan et al. 2011, Meisinger et al. 2008, Srivastava et al. 2018). Hence, in this study we divided the fertilized treatments (except CFT) into three stages namely, basal, tillering and panicle stages. Thus, despite higher nitrogen application, higher NUE and yield in RFT treatment compared to CFT might be attributed to such split application that led to availability of $\mathrm{N}$ in later rather important stages. This was proved with high PFP and AE in split applications in Fan et al. (2009).Temporally, grain yield peaked in 2014 and 2015 for rice, and 2010 for wheat. A slight yield decrease in the overall trend was observed in years, which could be attributed to $\mathrm{pH}$ decrease from long term fertilization. Acidity is a significant driving factor for yield decline through increasing and decreasing availabilities of $\mathrm{Al}$ and essential cations, respectively (Guo et al. 2010). The average grain yield of the fertilized treatments was 60 and $46.87 \%$ higher than the control treatment in rice and wheat growing seasons respectively. Their log transformed distribution showed significant differences. But the significance difference was only between control and fertilized treatments. There was no statistical difference among fertilized treatments.

\section{Table 3 near here}

\section{Fig 6-Rice and Fig-Wheat near here}

\section{Conclusion}

Grain and biomass yield on fertilized treatments was significantly higher than control treatment. Yield responses to fertilizer application were in order of HFT $>$ RFTS $>$ CFT $>$ RFT $>$ CK for paddy rice and RFTS $>$ HFT $>$ RFT $>$ CFT $>$ CK for wheat. Although there was slight variability within years but is was not statistically significant.

RFT and RFTS fell within the desired range for NUE. Over all, we can conclude that RFTS and RFT excel in effectiveness whereas, CT and HFT were less in that aspect.

Loading of nutrients in the reduced fertilization treatment was significantly lower than the other treatments. Buffering role of straw by increasing time lapse and decreasing velocity played important role in decreasing loading in RFTS. Wheat season loading was generally higher than rice season except for $\mathrm{NH}_{4}{ }^{+}-\mathrm{N}$.

In this research, we sought to assess possibility of maintaining crop yield while minimizing nutrient loading. Our findings illustrated, source control of nutrient management through reduced fertilization enhanced nitrogen use efficiency, increased nutrient retention, reduced nutrient export and maintained high crop yield. Reduction fertilization treatments RFT and RFTS met these desired targets.

We recommend testing more nutrient management practices, to extend the temporal trend and the spatial distribution, and to integrate experimental and model-based methods.

\section{References}

Barak, P., Jobe, B. O., Krueger, A. R., Peterson, L. A. \& Laird, D. A. 1997. 'Effects of long-term soil acidification due to nitrogen fertilizer inputs in Wisconsin.' Plant and Soil, 197:1, 61-69. 
Carpenter, S. R., Bolgrien, D., Lathrop, R. C., Stow, C. A., Reed, T. \& Wilson, M. A. 1998. 'Ecological and economic analysis of lake eutrophication by nonpoint pollution.' Australian Journal of Ecology, 23:1, 68-79.

Cassman, K. G., Dobermann, A. \& Walters, D. T. 2002. 'Agroecosystems, Nitrogen-use Efficiency, and Nitrogen Management.' AMBIO: A Journal of the Human Environment, 31:2, 132-40, 9.

Chen, X., Yang, X., Dong, X. \& Liu, E. 2013. 'Environmental changes in Chaohu Lake (southeast, China) since the mid 20th century: The interactive impacts of nutrients, hydrology and climate.' Limnologica, 43:1, $10-17$.

Duan, J., Shao, Y., He, L., Li, X., Hou, G., Li, S., Feng, W., Zhu, Y., Wang, Y. \& Xie, Y. 2019. 'Optimizing nitrogen management to achieve high yield, high nitrogen efficiency and low nitrogen emission in winter wheat.' Science of The Total Environment, 697, 134088.

Fan, M., Lu, S., Jiang, R., Liu, X. \& Zhang, F. 2009. 'Triangular Transplanting Pattern and Split Nitrogen Fertilizer Application Increase Rice Yield and Nitrogen Fertilizer Recovery.' Agronomy Journal,101:6, 142125.

Fan, M., Shen, J., Yuan, L., Jiang, R., Chen, X., Davies, W. J. \& Zhang, F. 2011. 'Improving crop productivity and resource use efficiency to ensure food security and environmental quality in China.' Journal of Experimental Botany, 63:1, 13-24.

Follett, R. F. 2008. 'Chapter 2 Transformation and Transport Processes of Nitrogen in Agricultural Systems.'

Gao, S., Tanji, K. K., Scardaci, S. C. \& Chow, A. T. 2002. 'Comparison of Redox Indicators in a Paddy Soil during Rice-Growing Season.'Soil Science Society of America Journal, 66:3, 805-17.

Guo, J. H., Liu, X. J., Zhang, Y., Shen, J. L., Han, W. X., Zhang, W. F., Christie, P., Goulding, K. W. T., Vitousek, P. M. \& Zhang, F. S. 2010. 'Significant Acidification in Major Chinese Croplands.'Science, 327:5968, 1008.

Hahn, C., Prasuhn, V., Stamm, C. \& Schulin, R. 2012. 'Phosphorus losses in runoff from manured grassland of different soil P status at two rainfall intensities.' Agriculture, Ecosystems 83 Environment,153, 65-74.

Hansen, A. T., Dolph, C. L., Foufoula-Georgiou, E. \& Finlay, J. C. 2018. 'Contribution of wetlands to nitrate removal at the watershed scale.' Nature Geoscience, 11:2, 127-32.

Hauck, R. D. 1981. 'NITROGEN FERTILIZER EFFECTS ON NITROGEN CYCLE PROCESSES.' Ecological Bulletins :33, 551-62.

Heuer, S., Gaxiola, R., Schilling, R., Herrera-Estrella, L., López-Arredondo, D., Wissuwa, M., Delhaize, E. \& Rouached, H. 2017. 'Improving phosphorus use efficiency: a complex trait with emerging opportunities.' The Plant Journal, 90:5, 868-85.

Ji, X.-H., Zheng, S.-X., Shi, L.-H. \& Liu, Z.-B. 2011. 'Systematic Studies of Nitrogen Loss from Paddy Soils Through Leaching in the Dongting Lake Area of China.' Pedosphere, 21:6, 753-62.

Jia, X., Zhu, Y., Huang, L., Wei, X., Fang, Y., Wu, L., Binley, A. \& Shao, M. 2018. 'Mineral N stock and nitrate accumulation in the 50 to $200 \mathrm{~m}$ profile on the Loess Plateau.' Science of The Total Environment, 633, 999-1006.

Jin, L., Cui, H., Li, B., Zhang, J., Dong, S. \& Liu, P. 2012. 'Effects of integrated agronomic management practices on yield and nitrogen efficiency of summer maize in North China.' Field Crops Research,134, 30-35.

Ju, X.-T., Xing, G.-X., Chen, X.-P., Zhang, S.-L., Zhang, L.-J., Liu, X.-J., Cui, Z.-L., Yin, B., Christie, P., Zhu, Z.-L. \& Zhang, F.-S. 2009. 'Reducing environmental risk by improving $\mathrm{N}$ management in intensive Chinese agricultural systems.' Proceedings of the National Academy of Sciences, 106:9, 3041. 
Lassaletta, L., Billen, G., Grizzetti, B., Anglade, J. \& Garnier, J. 2014. '50 year trends in nitrogen use efficiency of world cropping systems: the relationship between yield and nitrogen input to cropland.' Environmental Research Letters, 9:10, 105011.

Li, Q., Luo, Y., Wang, C., Li, B., Zhang, X., Yuan, D., Gao, X. \& Zhang, H. 2016. 'Spatiotemporal variations and factors affecting soil nitrogen in the purple hilly area of Southwest China during the 1980s and the 2010s.' Science of The Total Environment, 547, 173-81.

Luce, M. S. 2013. 'Labile organic nitrogen fractions: characteristics, dynamics and significance to soil nitrogen supply in agricultural soils.'

Meisinger, J. J., Schepers, J. S. \& Raun, W. R. 2008. 'Crop Nitrogen Requirement and Fertilization.' Nitrogen in Agricultural Systems, 563-612.

Mellander, P.-E., Melland, A. R., Jordan, P., Wall, D. P., Murphy, P. N. C. \& Shortle, G. 2012. 'Quantifying nutrient transfer pathways in agricultural catchments using high temporal resolution data.' Environmental Science 83 Policy, 24, 44-57.

Meng, Q., Yue, S., Hou, P., Cui, Z. \& Chen, X. 2016. 'Improving Yield and Nitrogen Use Efficiency Simultaneously for Maize and Wheat in China: A Review.' Pedosphere, 26:2, 137-47.

Ni, J., Xu, J. \& Zhang, M. 2018. 'Constructed wetland modelling for watershed ecosystem protection under a certain economic load: A case study at the Chaohu Lake watershed, China.' Ecological Modelling,368, 180-90.

Nie, X., Xiong, F., Yang, L., Li, C. \& Zhou, G. 2017. 'Soil Nitrogen Storage, Distribution, and Associated Controlling Factors in the Northeast Tibetan Plateau Shrublands.' Forests, 8:11.

Patrick, W. H. \& Mahapatra, I. C. 1968. 'Transformation and Availability to Rice of Nitrogen and Phosphorus in Waterlogged Soils.' In A. G. Norman (Ed.) Advances in Agronomy: 323-59. Academic Press.

Peng, Z., Hu, W., Liu, G., Zhang, H., Gao, R. \& Wei, W. 2019. 'Development and evaluation of a real-time forecasting framework for daily water quality forecasts for Lake Chaohu to Lead time of six days.'Science of The Total Environment, 687, 218-31.

Schroder, J. L., Zhang, H., Girma, K., Raun, W. R., Penn, C. J. \& Payton, M. E. 2011. 'Soil Acidification from Long-Term Use of Nitrogen Fertilizers on Winter Wheat.' Soil Science Society of America Journal, $75: 3,957-64$.

Srivastava, R. K., Panda, R. K., Chakraborty, A. \& Halder, D. 2018. 'Enhancing grain yield, biomass and nitrogen use efficiency of maize by varying sowing dates and nitrogen rate under rainfed and irrigated conditions.' Field Crops Research, 221, 339-49.

Swaney, D. P. \& Howarth, R. W. 2019. 'Phosphorus use efficiency and crop production: Patterns of regional variation in the United States, 1987-2012.' Science of The Total Environment, 685, 174-88.

Veneklaas, E. J., Lambers, H., Bragg, J., Finnegan, P. M., Lovelock, C. E., Plaxton, W. C., Price, C. A., Scheible, W.-R., Shane, M. W., White, P. J. \& Raven, J. A. 2012. 'Opportunities for improving phosphorususe efficiency in crop plants.' New Phytologist, 195:2, 306-20.

Wang, J., Lü, G., Guo, X., Wang, Y., Ding, S. \& Wang, D. 2015. 'Conservation tillage and optimized fertilization reduce winter runoff losses of nitrogen and phosphorus from farmland in the Chaohu Lake region, China.' Nutrient Cycling in Agroecosystems, 101:1, 93-106.

Wang, L., Liang, T. \& Zhang, Q. 2013. 'Laboratory experiments of phosphorus loss with surface runoff during simulated rainfall.' Environmental Earth Sciences, 70:6, 2839-46.

Wang, R., Min, J., Kronzucker, H. J., Li, Y. \& Shi, W. 2019. 'N and P runoff losses in China's vegetable production systems: Loss characteristics, impact, and management practices.' Science of The Total Environment, 663, 971-79. 
Yang, X., Lu, Y., Ding, Y., Yin, X., Raza, S. \& Tong, Y. a. 2017. 'Optimising nitrogen fertilisation: A key to improving nitrogen-use efficiency and minimising nitrate leaching losses in an intensive wheat/maize rotation (2008-2014).' Field Crops Research, 206, 1-10.

Zhang, Q.-c. \& Wang, G.-h. 2005. 'Studies on nutrient uptake of rice and characteristics of soil microorganisms in a long-term fertilization experiments for irrigated rice.' Journal of Zhejiang University. Science. B, 6:2, $147-54$.

Zhou, H. \& Gao, C. 2011. 'Assessing the Risk of Phosphorus Loss and Identifying Critical Source Areas in the Chaohu Lake Watershed, China.' Environmental Management, 48:5, 1033.

Zhou, J., Gu, B., Schlesinger, W. H. \& Ju, X. 2016. 'Significant accumulation of nitrate in Chinese semi-humid croplands.' Scientific Reports, 6:1, 25088.

China Statistical Yearbook on Environment. 2011. China Statistics Press . Beijing (Chinese)

People's Government of Anhui Province, Environmental Protection Department. 2011. Chao Lake Water Pollution Prevention Plan (2011-2015) . Hefei (Chinese)

Annex 1: treatment fertilizer application rates in paddy rice-wheat rotational tillage system (2008 -2018)

\section{Hosted file}

image1. emf available at https://authorea.com/users/367810/articles/487088-reduced-fertilizerrates-enhanced-nitrogen-use-efficiency-and-decreased-nitrogen-loading-in-paddy-ricewheat-long-term-rotational-cropping-in-chao-lake-watershed-east-china

\section{Hosted file}

List of Tables.pdf available at https://authorea.com/users/367810/articles/487088-reducedfertilizer-rates-enhanced-nitrogen-use-efficiency-and-decreased-nitrogen-loading-inpaddy-rice-wheat-long-term-rotational-cropping-in-chao-lake-watershed-east-china

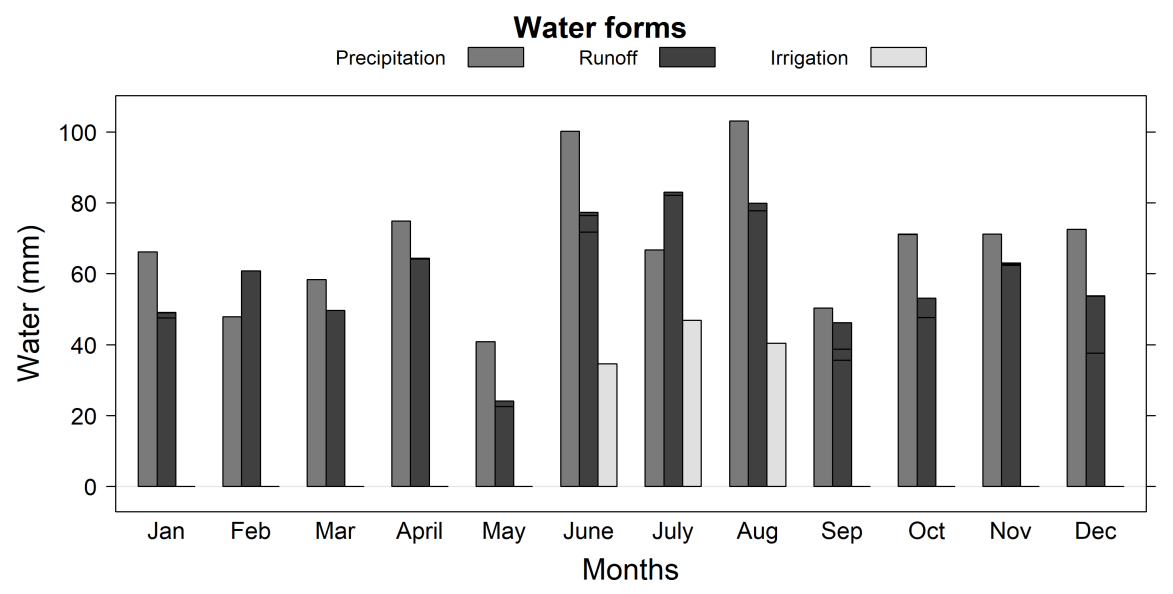



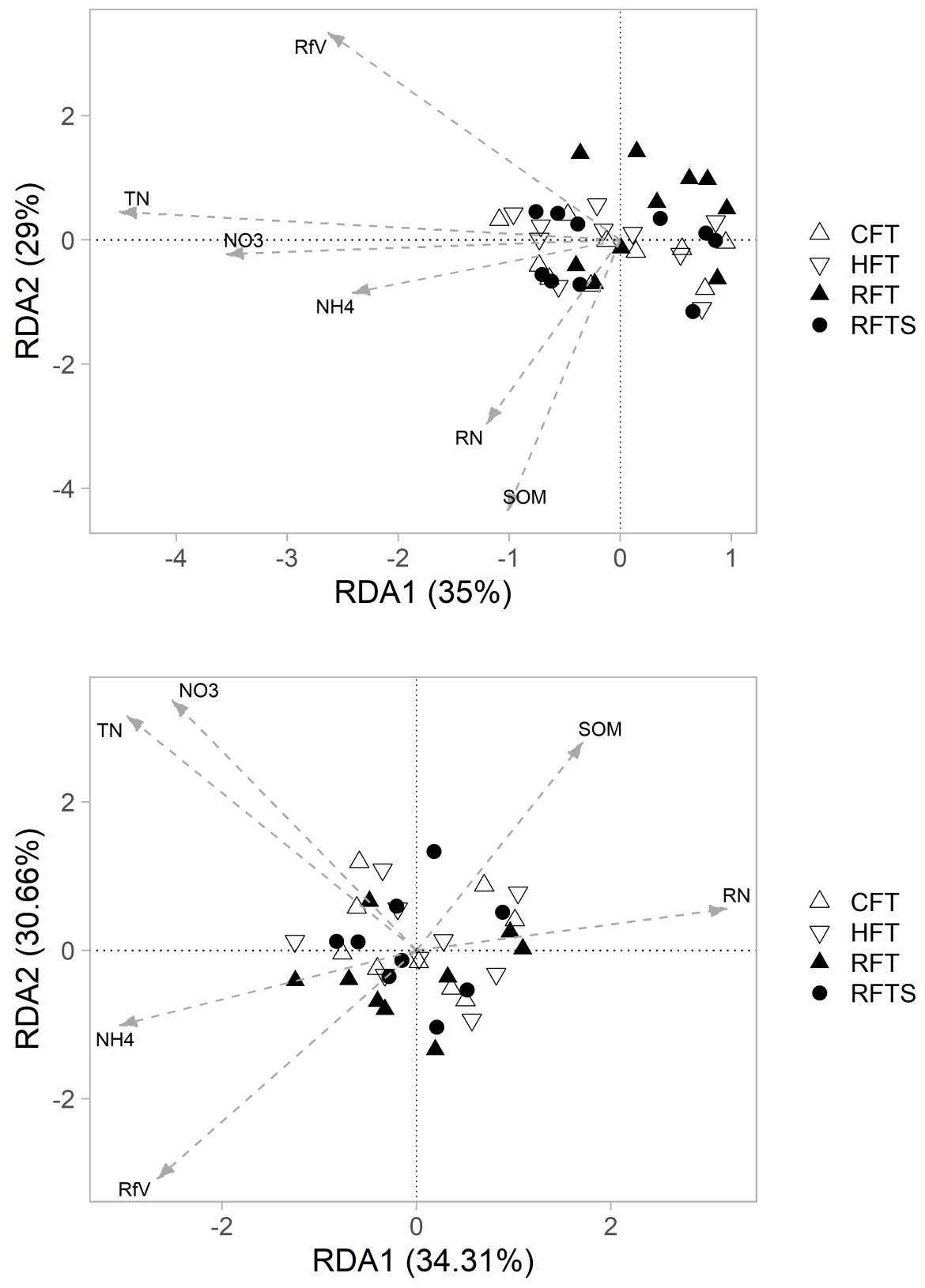

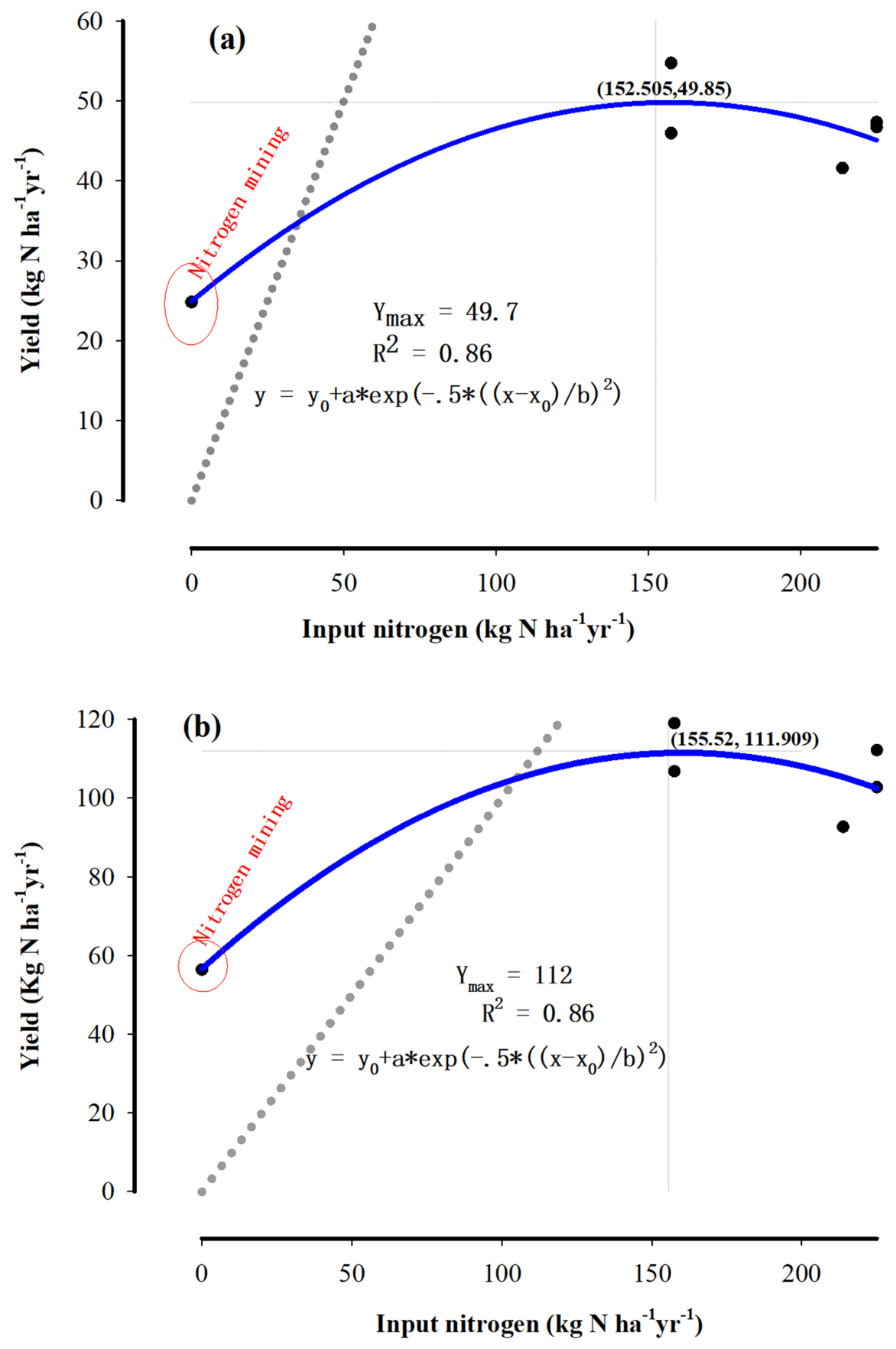

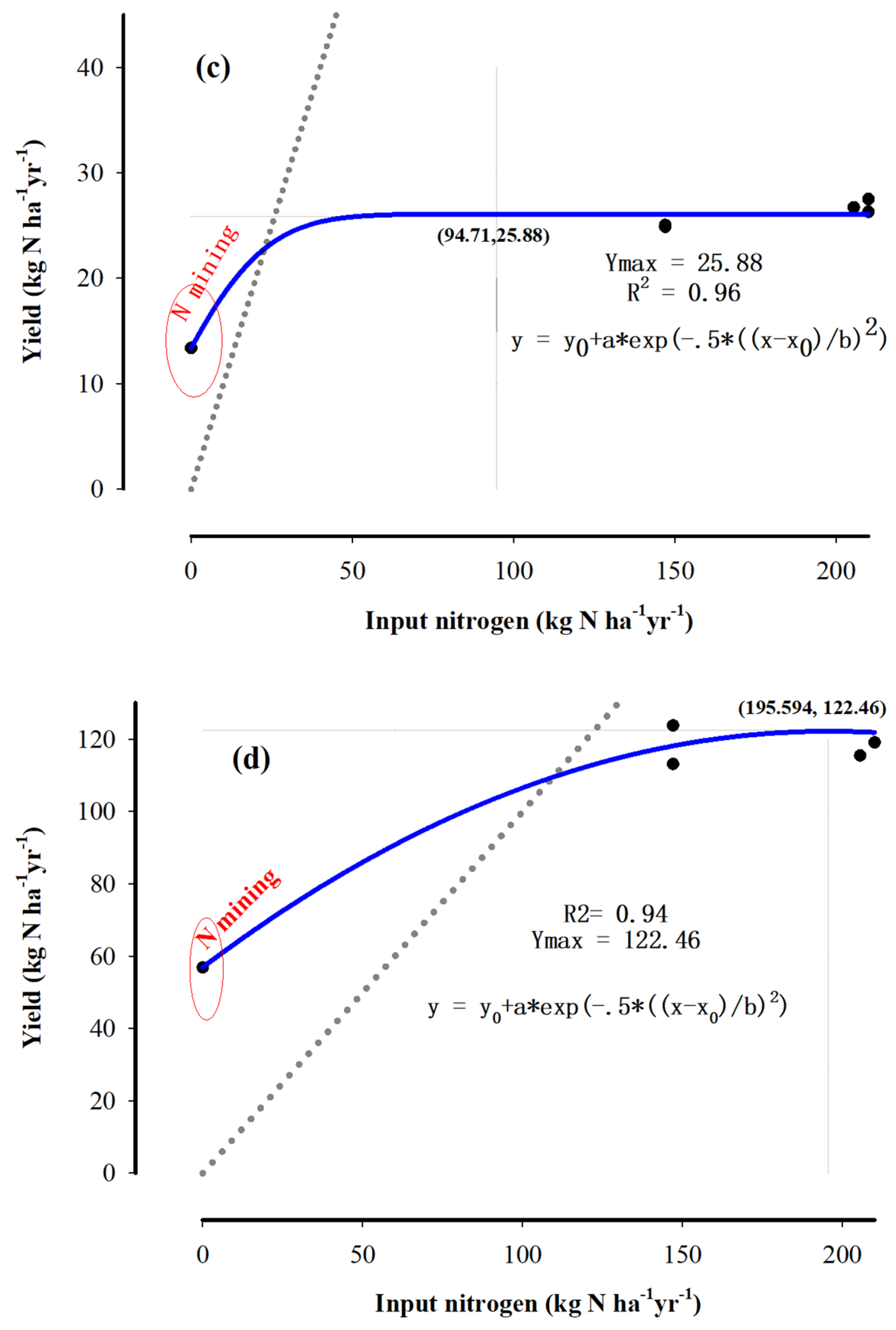


\section{Paddy rice season NUE}

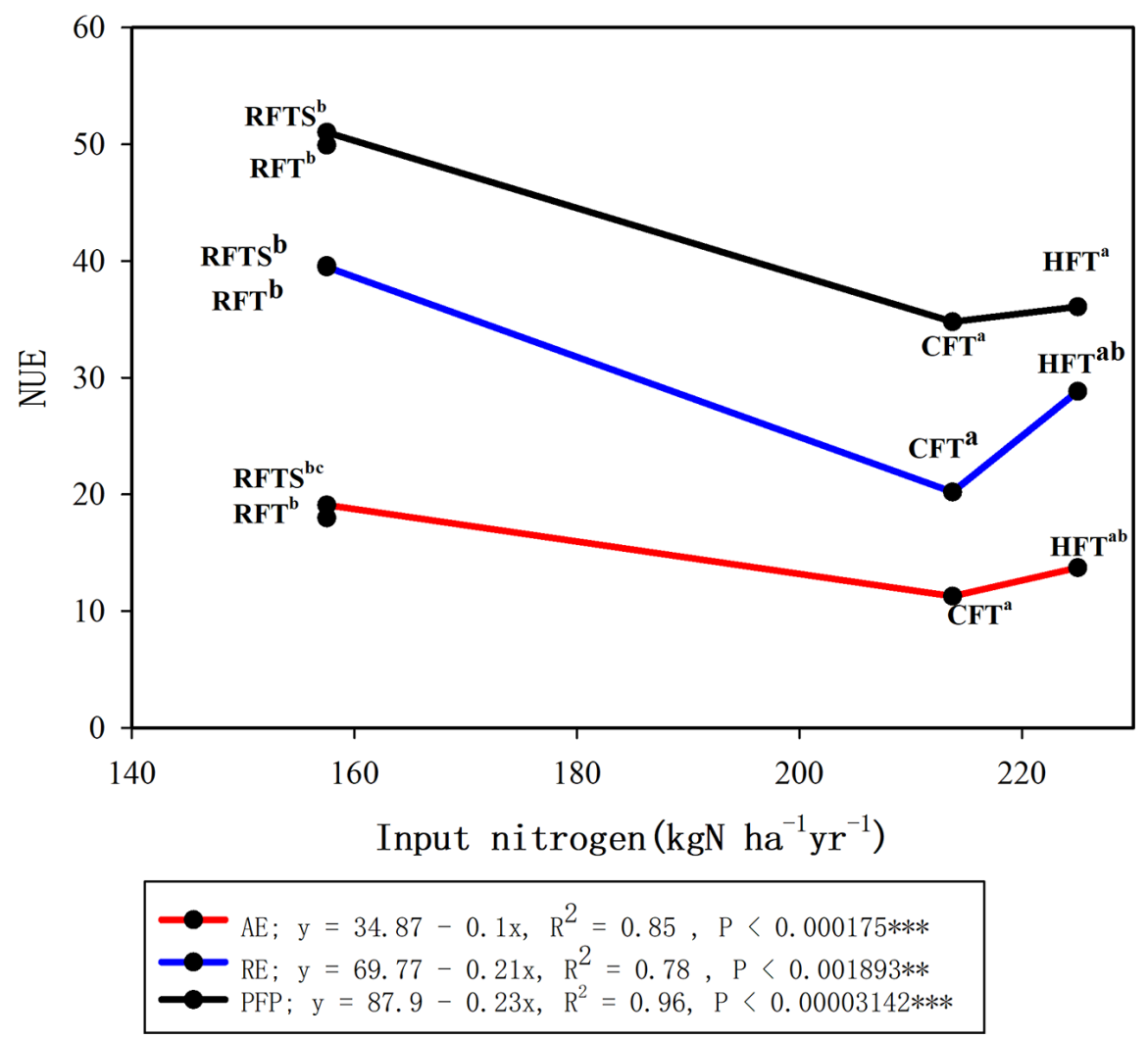


Wheat season NUE
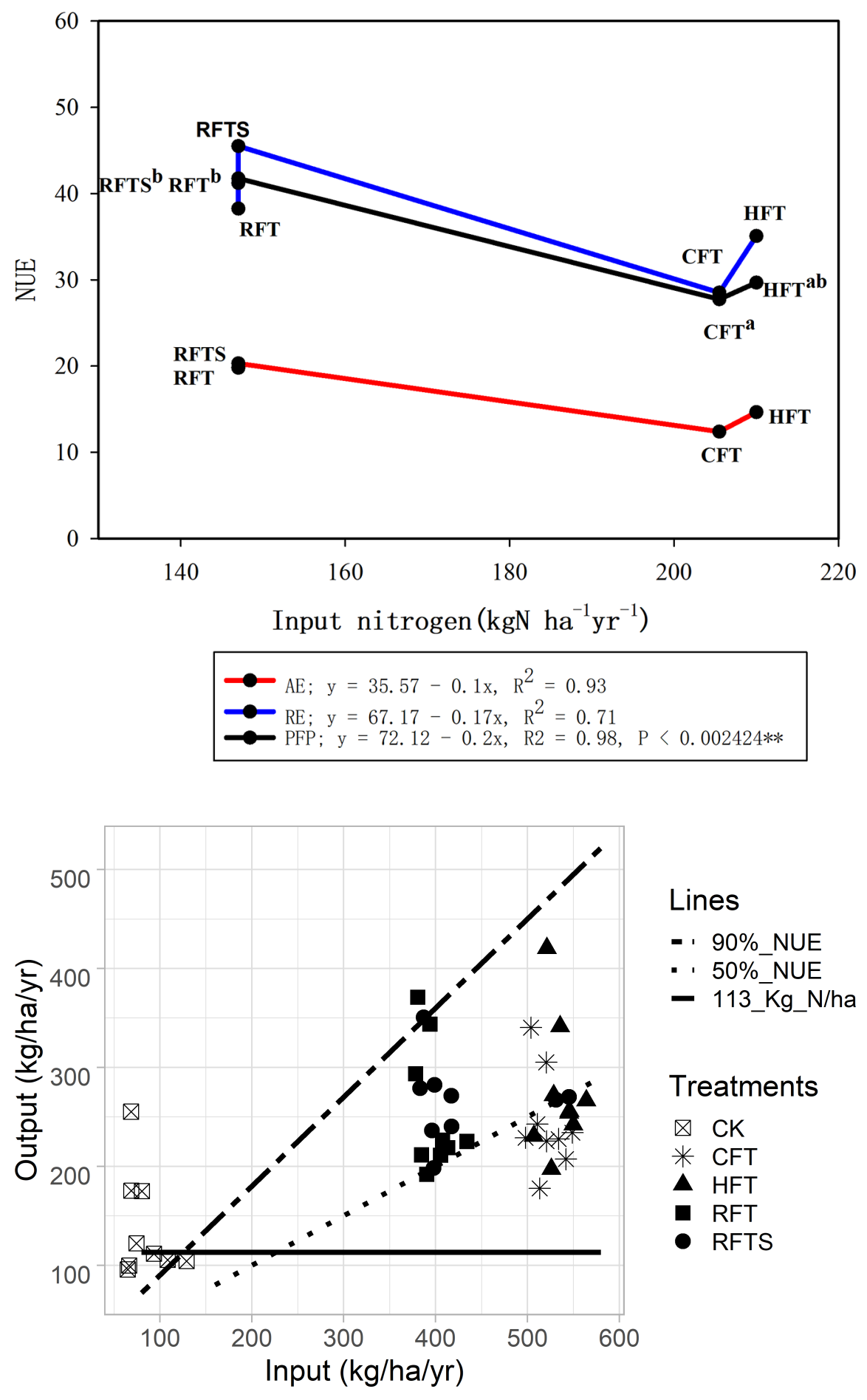
Paddy rice season NUE

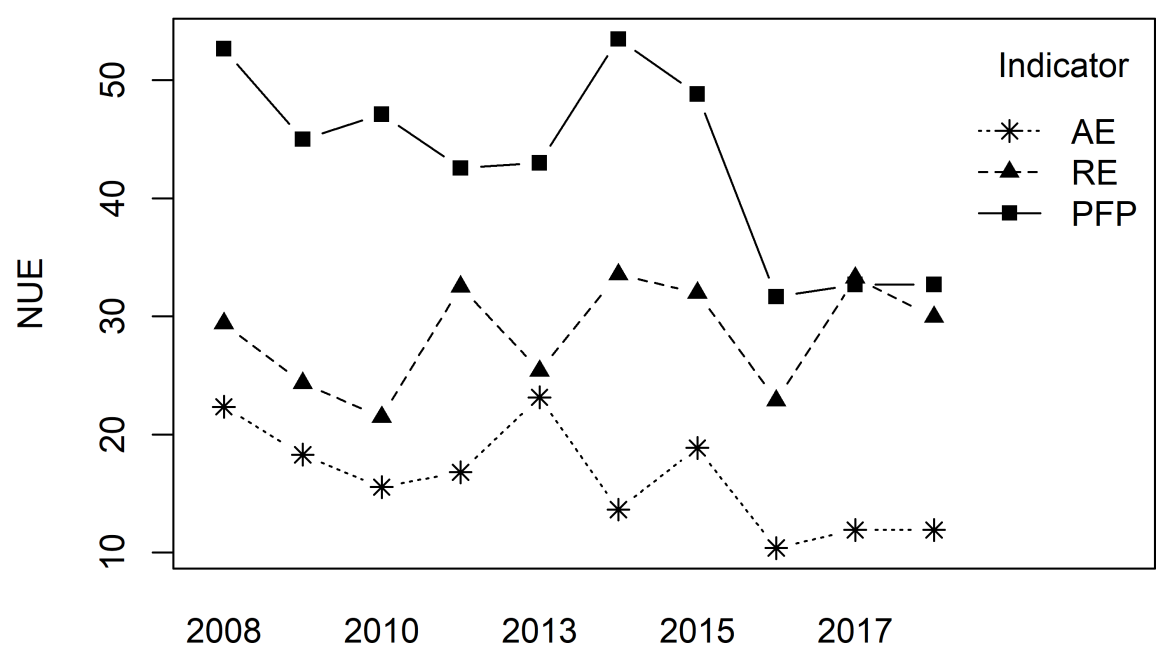

\section{Wheat season NUE}

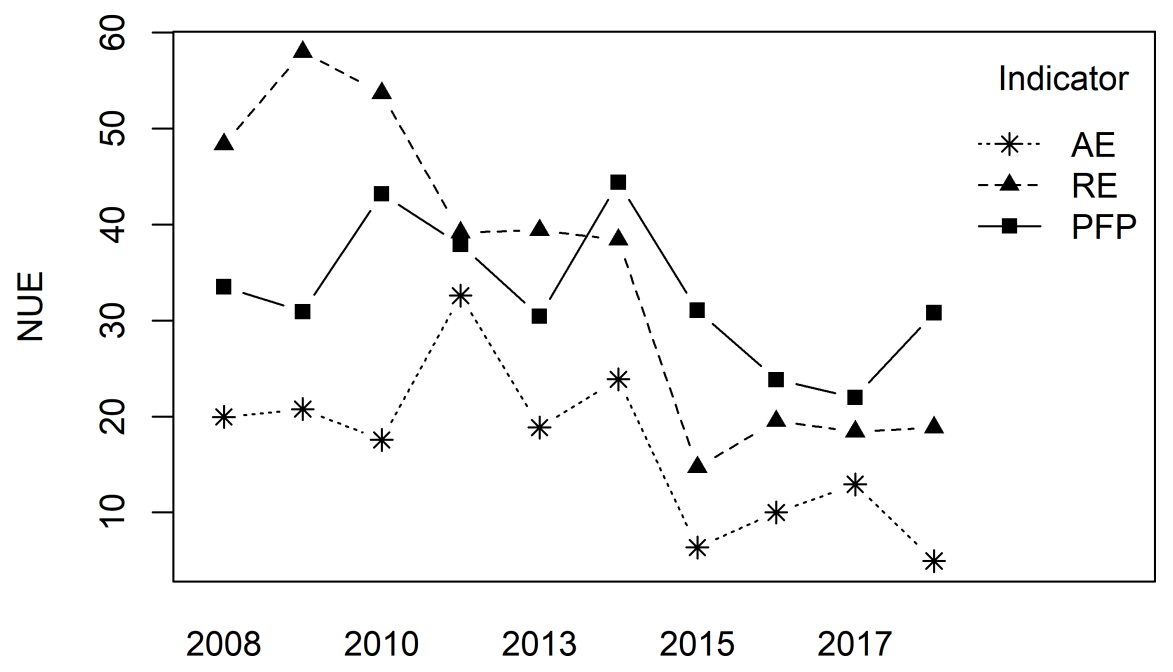

